\section{DESAFIOS DA (IN)FORMAÇÃO DOCENTE: O TRABALHO PEDAGÓGICO COM AS ARTES NA ESCOLARIZAÇÃO}

\author{
Ricardo 0 ttoni Vaz Japiassu*
}

Resumo: O artigo problematiza o lugar do ensino das Artes nos cursos e processos (in)formativos do educador no Brasil, sinalizando o paradigma práticoreflexivo de Schön enquanto via alternativa para correção das distorções constatadas na preparação do profissional da educação infantil e das séries iniciais do ensino fundamental. As experiências investigativas e reflexivas do autor são utilizadas como matéria-prima dos argumentos teóricos aqui utilizados. Adicionalmente, considera as diferentes conceptualizações de letramento subjacentes às macro e micropolíticas educacionais para a educação infantil e séries iniciais do ensino fundamental, como forma de problematizar o lugar do ensino de Arte na escolarização.
Palavras-chave: Arteeducação. Educação infantil. Ensino de arte. Formação de professores. Paradigma crítico-reflexivo.

*D outor em Educação emestreem Artes-USP; Licenciado ebachare en Teatro, UFBA; Professor, U NEB. rjapias@uol.com.br

Recebido em: 19 fev 2004 Aprovado em: 16 mar. 2004
$\mathrm{R}$
$\mathrm{E}$
$\mathrm{V}$.
$\mathrm{C}$
$\mathrm{I}$
$\mathrm{E}$
$\mathrm{N}$
$\mathrm{T}$. 
${ }^{1} \mathrm{O}$ termo '(in)formação' busca referir a complexidade das práticas formativas de professores no âmbito da sociedade do conhecimento (ou da informação) e destacar 0 aproveitamento e uso sistemático da informação no processo da formação profissional de educadores.

\section{Ensino de arte e formação de professores}

0 problema relativo ao ensino das artes no país põe em xeque a formação de professores oferecida nas licenciaturas em Arte (Artes V isuais, D ança, M úsica e Teatro), nos cursos de Pedagogia, em escolas normais superiores, habilitações para o M agistério de nível médio e em programas para 0 aperfeiçoamento, em serviço, do educador (SAntana, 2000; Penna, 2001).

Que tipo de (in)formaçãa $0^{1}$ os profissionais da educação recebem para trabalhar com seus alunos, de modo sistemático, as diferentes linguagens artísticas? Se a habilitação para o M agistério na educação infantil e séries iniciais do ensino fundamental é prerrogativa do pedagogo, por que nos cursos de Pedagogia e de formação de professores não são oferecidas disciplinas que contemplem a especificidade estética de cada uma das linguagens artísticas (Artes Visuais, Dança, Música e Teatro)? Por que não se busca sinalizar procedimentos metodológicos para o trabalho sistemático com cada uma das linguagens artísticas em cursos que têm como objetivo a formação dos profissionais da educação que irão atuar nas creches, préescolas e séries iniciais do ensino fundamental? Se cabe aos artistas, arte-educadores e aos professores de arte 0 trabal ho pedagógico com as artes na educação infantil e séries iniciais do ensino fundamental (da 1a à 4a série) por que é tão rara a presença desses profissionais nestes níveis da escolarização básica?

Parecenos que evitar a formulação de questões como as apresentadas - ou não procurar respondêlas - revela uma silenciosa orquestração na direção de "deixar tudo como está pra ver como é que fica"; por isso, queremos aqui expor nosso ponto de vista em relação a essa problemática.

Se, por um lado, não temos a ambição de ser 'donos da verdade', por outro, propomos um equacionamento não desinteressado do problema. Entendemos que o professor da educação infantil e das séries iniciais é essencialmente polivalente, ou seja, é aquele profissional 'licenciado' para realizar a transposição didática do conhecimento das diferentes áreas do saber em creches, préescolas e nas séries iniciais do ensino fundamental (da 1a à $4^{a}$ série). $\mathrm{N}$ ão se tem notícia de professores de matemática ou de língua portuguesa, por exemplo, atuando na educação infantil e nas quatro primeiras séries do ensino 
fundamental: as licenciaturas nessas duas áreas têm em vista o exercício do magistério da 5 a à 8 a série do ensino fundamental e ao longo do ensino médio, e o mesmo ocorre com as licenciaturas para 0 ensino das demais áreas do conhecimento: Artes, Educação Física, Ciências N aturais, H istória e G eografia (BRASIL, 1997, 1998).

Se é assim, os cursos de Pedagogia precisam, do nosso ponto de vista, assumir a especificidade da formação profissional que se propõem a oferecer, criando condições de igualdade no oferecimento das diretrizes metodológicas para o trabalho pedagógico com todas as áreas de conhecimento. Afinal, a licença para o exercício do magistério na educação infantil e séries iniciais do ensino fundamental é prerrogativa do pedagogo.

Essa licença é o 'caroço' de sua identidade profissional. Abrir mão disso significa pôr em risco a existência dos cursos de Pedagogia. É necessário, portanto, o compromisso das faculdades de educação com a elaboração de uma matriz curricular que não comprometa a excelência do ensino de Arte que os artistas, arte-educadores e professores de arte brasileiros almejam e têm perseguido historicamente (J APIASSU, 2003a, p. 49-54).

Para utilizar nosso próprio exemplo, temos lecionado unicamente M etodologia do Ensino de ArtesVisuais, embora M etodologia do Ensino de D ança, M etodologia do Ensino de Teatro e M etodologia do Ensino de M úsica devessem compor a matriz curricular dos cursos de Pedagogia nos quais atuamos. 0 fato é que nenhuma dessas linguagens costuma ser trabal hada satisfatoriamente com os futuros professores, na mai oria dos cursos de (in)formação do educador e de Pedagogia no país.

0 leitor certamente questionará as razões pelas quais um especialista em Artes Cênicas conduz intervenções pedagógicas utilizando Artes Visuais. Esclarecemos: em primeiro lugar, até o presente, só foi possível 'encaixar' uma única linguagem artística na matriz curricular dos cursos de Pedagogia da Instituição de Ensino Superior (IES) em que atuamos. Em parte, isso já significa um avanço, a despeito de ainda permanecer, no senso comum, o entendimento de que o ensino de Arte deve ser um mosaico 'condensado' das diferentes formas de expressão estética. 0 fato é que a linguagem das Artes V isuais foi 'eleita' para ser prioritariamente trabalhada com os futuros professores, em razão de a 
construção dos processos de representação do desenho e da escrita possuir, no início, uma trajetória comum. Para nós, é conveniente que se focalize apenas uma das linguagens artísticas em vez de 'borboletear', de modo superficial e insuficiente, pelo vasto universo das artes, mesmo considerando inconsistente 0 fato de (in)formar professores priorizando-se uma única linguagem artística; em segundo lugar, nosso engajamento no ensino de Artes Visuais ocorre sem prejuízo da qualidade de nossas intervenções pedagógicas com essa linguagem artística, porque nos sentimos muito à vontade para conduzir essa disciplina por: a) estarmos atentos ao desenvolvimento da área de Artes Visuais no Brasil por meio de publicações especializadas (BARBOSA, 1996; DEHEIZELIN, 1998; Ferraz; FusARI, 1993a, 1993b; M OREIRA, 1984; PILlar, 1993, 1996a, 1996b); b) participarmos freqüentemente de encontros (virtuais e presenciais) promovidos pela Federação de Arte-Educadores do Brasil (FAEB), e c) interessarmo-nos pelos eventos promovidos sob a curadoria da professora doutora Ana M ae Barbosa, pioneira do ensino de Arte na perspectiva da pósmodernidade no país; 3 ) em terceiro, isso se justifica em razão do nosso interesse pelo estudo da estética do grafismo infantil na perspectiva da psicologia sóciohistórica e de sua teoria histórico-cultural da atividade (AzENHA, 1995; DE Camillis, 2002; Ferreira, 1998; LeVIn, 1998; LuRIA, 1994; M arín, 1985; RocCo, 1990; VYGOYSKY, 1982, 1996, 1998, 2001).

A discussão sobre a quem cabe a responsabilidade do ensino das artes na educação infantil e séries iniciais do ensino fundamental é oportuna. $E$ já nos posicionamos claramente em relação isso: reiteramos que o ensino de Arte nesse nível da educação básica é uma prerrogativa do pedagogo, ou seja, do profissional da educação, (in)formado e licenciado para exercer ali o magistério. M as é preciso observar que, "nas primeiras quatro séries do ensino fundamental, costuma atuar um professor com formação de nível médio, totalmente despreparado para uma prática pedagógica consistente na área de Arte" (PEN NA, 2001, p. 53). O ra, defender o ensino de Arte na educação infantil e séries iniciais do ensino fundamental como prerrogativa do pedagogo não significa excluir a possibilidade de 0 artista, 0 arte-educador e 0 licenciado para 0 ensino das diferentes linguagens artísticas (Artes V isuais, D ança, M úsica e Teatro) atuarem com os profissionais da educação infantil e séries iniciais do ensino 
fundamental. ${ }^{2}$ Evidentemente, os licenciados em Arte, os arte-educadores e os artistas, para poderem atuar de modo conseqüente na educação infantil e séries iniciais da educação básica, necessitam de (in)formações adequadas e específicas que Ihes assegurem o gerenciamento competente de suas intervenções pedagógicas nesses níveis da escolarização.

Por esses motivos, entendemos que a questão principal continua sendo a (re)conceptualização dos processos (in)formativos dos profissionais da educação na perspectiva da melhoria de sua performance enquanto trabalhadores altamente qualificados para o desenvolvimento das ações educacionais. Nesse sentido, um caminho alternativo tem-se revelado promissor no ensino de Arte: a formação continuada e em serviço de professores numa perspectiva prático-reflexiva (SCHÖN, 1987). Esse paradigma formativo reserva para a pesquisa-ação lugar central no processo de (in)formação profissional do educador porque o professor-cursista (re)faz a sua prática pedagógica a partir da reflexão 'em ação' e 'sobre a ação', nas intervenções educativas das quais participa. A natureza improvisacional desse paradigma aponta para o desafio do 'novo', enfatizando a atividade criadora e o 'jogo de cintura' necessário ao professor-pesquisador, em sala de aula ou nos ambientes digitais de aprendizado.

Algumas experimentações na perspectiva desse 'novo' paradigma de formação têm sinalizado claramente a eficácia do modelo formulado por $D$ onald Schön, como solução emergencial para as lacunas observadas nos processos (in)formativos institucionais dos trabalhadores da educação, porque "a orientação e acompanhamento da prática desses professores, num processo reflexivo, pode possibilitar uma produtiva atuação na área de Arte." (PENNA, 2001, p. 54).

\section{A prática reflexiva e o trabalho pedagógico com Arte/Teatro}

Para demonstrar ao leitor algumas possibilidades do paradigma reflexivo na formação continuada e em serviço de educadores para o trabalho pedagógico com Arte/Teatro, passamos a expor os resultados obtidos com uma pesquisa-intervenção desenvolvida em uma préescola da rede pública municipal de São Paulo.
${ }^{2}$ Vale lembrar que a Prefeitura de São Paulo, recentemente, fez concurso público para o ensino deArtenosCentrosEducacionais Unificados (CEUs), abrindo acertadamente inscrições para licenciados em Arte, artistas e arte-educadores. 
A pesquisa tinha por objetivo geral promover o desenvolvimento da capacidade estética em préescolares (BRASIL, 1998; VYGOTSKY, 1982). As propostas ludopedagógicas para a atividade teatral apresentadas às crianças foram conduzidas por uma professora regular da pré-escola, sob orientação do pesqui sador. 0 sistema de jogos teatrais (SPO LIN, 1992, 1999, 2001) serviu de ponto de apoio para a intervenção pedagógica desenvolvida com os pré-escolares (J APIASSU, 2003a). As sessões de jogos teatrais eram precedidas por sessões de planejamento e avaliação que ocorriam sempre no mesmo dia e horário previamente reservados ao trabalho. Assim, cada uma delas era planejada pelo pesqui sador e pela professora com uma semana de antecedência em relação à sua subseqüente implementação.

A partir da segunda sessão de jogos teatrais, na abertura de todos os encontros de planejamento-avaliação, discutiam-se os resultados da sessão de jogos desenvolvida na semana anterior. Para isso, professora e pesquisador: consultavam os registros em foto-áudio-vídeo do trabalho com as crianças, refletiam conjuntamente sobre o processo de trabalho, discutiam e planejavam as propostas para atividade teatral que seriam apresentadas aos pré-escolares nas sessões subseqüentes.

0 fato de a professora não possuir prática na condução do trabalho pedagógico com Arte/Teatro levou a pesquisa a configurar-se como aperfeiçoamento em serviço daquela profissional da educação. Ao todo ocorreram 15 sessões de planejamento-avaliação e 14 de jogos teatrais, perfazendo um total de 29 sessões de trabalho ao longo do ano letivo. 0 relatório completo da experimentação dessa proposta metodológica para 0 trabalho pedagógico com a linguagem teatral na educação infantil foi apresentado à Faculdade de Educação da Universidade de São Paulo (FEUSP) como tese de doutorado (J APIASSU, 2003b).

$\mathrm{N}$ a primeira sessão de trabalho com as crianças, após toda uma série de encontros prévios com a professora nos quais se buscara discutir, preparar e planejar as suas intervenções pedagógicas com Arte/Teatro, alguns problemas surgiram, entre eles a ansiedade típica de uma 'estréia' que não permitiu à professora seguir rigorosamente os procedimentos operacionais necessários à implementação do sistema de Spolin. Na ocasião, poderíamos têla 'corrigido', 
mas consideramos inoportuna qualquer intervenção. Como era seu début na condução do trabalho com jogos teatrais, julgamos prudente, para evitar ainda mais constrangimento, não objetar sua atuação na frente das crianças, o que a deixaria ainda mais nervosa. Preferimos aguardar o encontro de avaliaçãoplanejamento para analisar, com calma - e algum distanciamento crítico -, o videorregistro da sessão.

\title{
Professora
}

Eu tava tensa, e acabei me esquecendo [...]

Vale a pena chamar atenção do leitor, neste ponto, para o importante papel do videorregistro como ferramenta na (re)orientação da atuação e desempenho da professora na condução do trabalho pedagógico com Arte/Teatro. Veja-se o que disse a professora a esse respeito:

\begin{abstract}
Professora
Antes, era uma coisa que eu não percebia. E o vídeo, ele nos traz a prática [...] Eu acho que todos os professores deveriam filmar uma aula sua pra depois estarem se analisando [...] muitas coisas eu descobri sobre mim [... ] Assim: a postura, a entonação de voz, o jeito de falar, o olhar [...] Eu refleti sobre bastante coisas [...] É muito importante você estar revendo um trabalho com imagens, porque aquilo realmente aconteceu [...] Então, muitas coisas não são percebidas durante a ação da gente. Com o vídeo, há oportunidade de a gente estar falando: "Puxa, isso foi bacana! Já, aquilo lá não foi legal, eu poderia ter feito de uma outra maneira. Da próxima vez vai ser melhor!" N ossa, para mim, o uso do vídeo é uma auto-reflexão!
\end{abstract}

A recordação estimulada - por meio do vídeo, no caso - oferece a possibilidade de um distanciamento crítico das nossas ações, necessário a uma reflexão desapaixonada sobre o próprio comportamento. A auto-análise da professora sinaliza claramente novos caminhos a serem percorridos por ela no ensino de Arte/Teatro, superando-se a dicotomia processo-produto que tem caracterizado, em geral, a verificação do aprendizado nos processos (in)formativos institucionais. A auto-avaliação da professora, nesse caso, ocorre prospectivamente, ou seja, tendo como foco a apropriação cada vez maior dos 
procedimentos operacionais necessários à implementação do sistema de jogos teatrais para os pré-escolares. Essa visão prospectiva do seu desenvolvimento profissional, isto é, esse entendimento da provisoriedade dos resultados obtidos ao longo do processo de trabalho com Arte/Teatro liberta professores ealunos da valorização excessiva de apenas um determinado produto e da ênfase exagerada em um resultado que unicamente se relaciona a determinado momento da sua trajetória de desenvolvimento como profissional da educação infantil ou como sujeito do conhecimento.

\section{Professora}

Eu acho que essa revisão que a gente faz depois [nos encontros de avaliação] é muito importante. Para a gente estar avaliando o que está sendo bom, e o que não tá. Então, essa avaliação, ela nos dá a oportunidade de estar revendo as propostas, de avaliar o que é melhor, o que funciona mais [...] Acho isso bárbaro! Eu acho que esse tempo de 15 dias é um tempo superbom para a gente tá refletindo. E para as crianças também [...] Percebi que é importante ter todos aqueles momentos: de você sentar, de você conversar com eles [...] M inha postura mudou bastante: estar observando mais certas coisas neles; deixar a espontaneidade deles fluir [...] Porque, às vezes, a gente é muito... a gente quer dirigir o tempo todo as ações da criança e essa era uma conduta que eu tinha mesmo antes do início desse nosso trabalho. Essa postura minha mudou bastante!

Importante apresentar aqui o depoimento do coordenador pedagógico da pré-escola, para que o leitor possa ter uma visão mais nítida do processo (in)formativo em serviço desencadeado com a pesquisa:

\section{Coordenador pedagógico}

0 que eu tenho sentido é que o trabalho tem fluído de uma forma bastante objetiva e realmente as nossas expectativas... estão se consolidando. Esse projeto, para a gente, vai ser um ganho, em todos os aspectos. Através do vídeo, deu para perceber, realmente, a evolução da primeira sessão para a segunda [... A A idéia é abrir [o trabalho] para - grupo todo. A professora, pelo que ela nos conta, está superempolgada. 0 trabalho está fluindo[...] É por aí. 
0 paradigma prático-reflexivo constitui uma modalidade do método "intrumento-eresultado" (N EWMAN; H oLZMAN, 2002), isto é, trata-se de um saber-fazer que é, ao mesmo tempo, recurso e fruto da atividade (co)laborativa dos sujeitos por ele enredados. Os depoimentos - tanto o do coordenador pedagógico da préescola quanto o da professora acompanhada - revelam essa dimensão (in)formativa da intervenção pedagógica desenvolvida na educação infantil. Q uer dizer, além de ter-se constituído como experimentação de uma proposta metodológica para o trabalho sistemático com a linguagem teatral, numa perspectiva lúdica e improvisacional, a pesquisa repercutiu na prática pedagógica com Arte/Teatro da professora auxiliar do projeto.

\begin{abstract}
Professora
Mudou totalmente a minha concepção de trabalho com Teatro na educação infantil [... ] Antes, para mim, Teatro era montar uma peça com as crianças, uma dramatização [... ] para apresentar para alguém [... . Para mim, o trabalho com Teatro se resumia a isso [... ] E hoje, eu vejo que não [...] Para mim, o Teatro, antes, era uma coisa assim: [...] ali (na sala de aula) eles (as crianças) iam comunicar alguma coisa que a gente (professores) tinha escrito... Então não tinha a possibilidade de improvisação [...] que é o deixar a história ir rolando e ir se comunicando... . Então, nossa, é totalmente diferente... Talvez seja por isso que as pessoas não dêem importância, achem que esse seja um trabalho muito específico que tem de ser para uma escola de formadores de atores mirins... Eu acho que não é nada disso, é algo importante para o ser humano [... ] deles (os pré-escolares) estarem se comunicando, se expressando [... ] Eu acho que as crianças que estão participando desse projeto são crianças que vão se comunicar com muito mais facilidade... vão poder estar se expressando de diferentes formas... porque a gente está valorizando essas outras formas [... ] Então, a idéia que eu tinha de um trabalho pedagógico com o Teatro, antes, o ano passado, e hoje, nossa, é totalmente diferente!
\end{abstract}

Essa multidimencionalidade das pesquisas ancoradas no modelo práticoreflexivo só pode ser alcançada por investigações-ações quetenham o compromisso com o desenvolvimento de uma abordagem qual itativa de seus objetos de estudo. Antes de ser um 'instrumento-para-resultado' a observação participante que se desenvolveu na préescola busca existir, do ponto de vista metodológico, enquanto 
interferência social no desenvolvimento histórico dos sujeitos por ela enredados, ou seja, ambiciona tomar o papel de 'instrumento-e-resultado'.

Os depoimentos da professora que aqui foram apresentados são úteis também para confirmar haver, por parte dela, genuíno movimento de aproximação dos conceitos teatrais trabalhados com os pré-escolares, que eram sistematicamente solicitados a se comunicar pela linguagem cênica de natureza improvisacional com os jogos propostos. Como se poderá constatar a seguir, 0 paradigma prático-reflexivo da pesquisa levou a professora a (co)laborar um saber-fazer pedagógico com Arte/Teatro até então ignorado por ela.

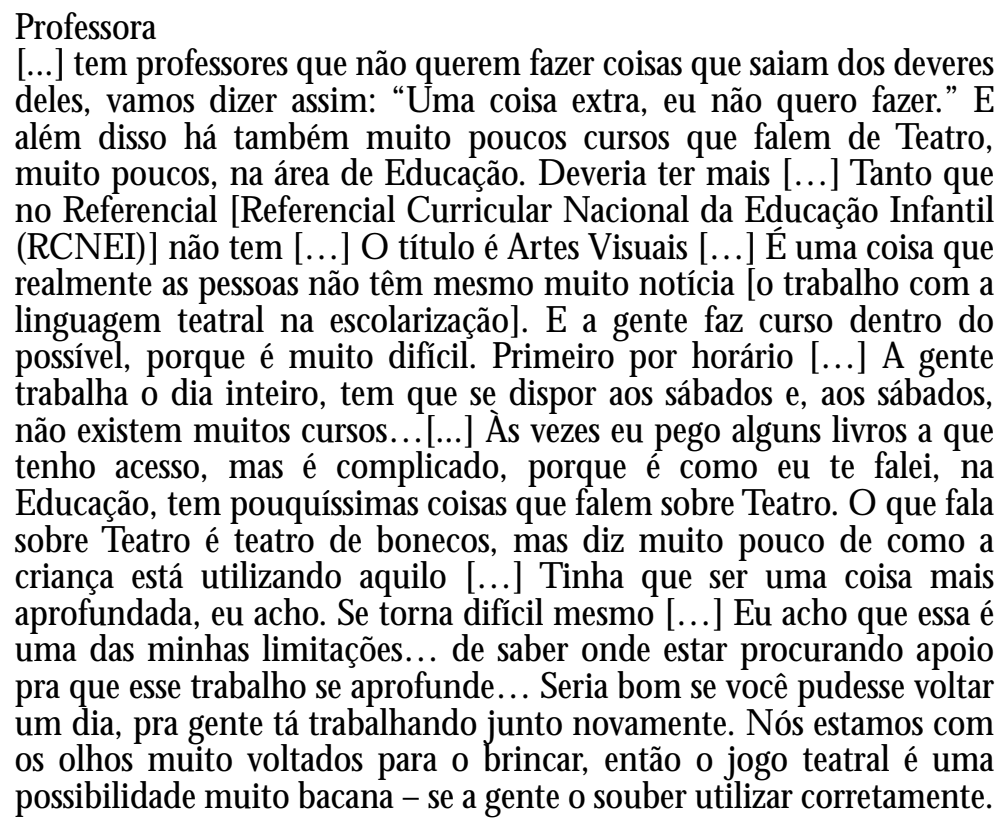

A fala da professora ratifica o que se advoga aqui, isto é, a urgência de uma melhor (in)formação do profissional da educação que atua na educação infantil e nas séries iniciais do ensino fundamental no que se refere ao ensino de Arte. 


\section{A prática pedagógica com Arte e as concepções de letramento na escolarização}

É inócua qualquer tentativa de problematizar o lugar do ensino de Arte na escolarização quando não levamos em consideração as diferentes conceptualizações de letramento subjacentes às macro e micropolíticas educacionais para a educação infantil e séries iniciais do ensino fundamental.

0 trabalho do(a) professor(a) nesses níveis da educação básica não pode nem deve resumir-se unicamente a ensinar às crianças como contar, escrever e ler! Isso equivale a nivelar por baixo os processos pedagógicos de desenvolvimento cultural das novas gerações, omitindo sua amplitude sóciohistórica e complexidade psicológica.

É estarrecedor constatar que o relatório final do Grupo de Trabalho (GT) Alfabetização Infantil, da Comissão de Educação e Cultura da Câmara dos D eputados - Alfabetização infantil: os novos caminhos - relatório final -, sinalize claramente a retomada de um modelo 'tecnicista' para o letramento, a reboque de uma ideologia neoliberal perversa, cuja ênfase recai exclusivamente na leitura, na escrita e na aritmética. ${ }^{3}$ Veja-se o que diz este documento quando critica as práticas correntes de (in)formação contínua e em serviço de educadores no país:

U ma das deficiências dessa capacitação é que ela se apóia em idéias e conceitos gerais e na idéia de que cabe ao professor conceber seus próprios materiais didáticos [sic] - o que entra em conflito com a prática da maioria dos professores, no Brasil e no mundo, que é a de se apoiar em materiais pedagógicos existentes. (BRASIL, 2003, p. 145).

No trecho transcrito, defendese claramente uma prática pedagógica escolar de natureza 'homogeneizante' que não considera a diversidade de contextos socioculturais da escolarização nacional nem a singularidade dos processos de intervenção educacional, caracterizando-0s, todos, como 'deficientes' em razão da idéia de que os professores possuem autonomia para a gestão (co)laborativa do conhecimento com seus alunos e a comunidade acadêmico-escolar. Aliás, a própria escolha do termo 'alfabetização' para referir a dinâmica do modo particular de letramento promovido pela escolarização, eque
${ }^{3}$ Parlamentares membros da Comissão de Educação e Cultura da Câmara dos D eputados: D ep. Gastão Vieira (PM D B-M A), Dep. Jonival Lucas Jr. (PTB-BA), Dep. Profesora Raquel Teixeira (PMDB-GO), Dep. Lobbe $N$ eto (PSD B-SP); $M$ embros do Grupo de Trabalho Alfabetização Infantil: Profa. Dra. Claudia C ardoso-M artins (UFM G), Prof. Dr. Fernando Capovilla (USP), Prof. Dr. Jean-Emile Gombert (Universidade de Rennes), João Batista Araújo e Oliveira (especialista em educação da JM Associados), Prof. Dr. José Carlos Juca de Morais (Universidade Livre de Bruxelas), Profa. Dra. M arilyn Jaeger Adams (U niversidade de $\mathrm{H}$ arvard) e Prof. Dr. Roger Beard (Universidade de Leeds). 
dá título ao documento, já diz muito do lugar de onde o grupo de trabalho da Comissão de Educação e Cultura da C âmara se propõe a olhar para a aquisição das competências necessárias à apropriação da cultura letrada.

O conceito de letramento começou a ser usado nos meios acadêmicos numa tentativa de separar os estudos sobre o 'impacto social da escrita' (KLEIM AN, 1991) dos estudos sobre a alfabetização, cujas conotações escolares destacam as competências individuais no uso e na prática da escrita. [...] Podemos definir hoje o letramento como um conjunto de práticas sociais que usam a escrita, enquanto sistema simbólico e enquanto tecnologia, em contextos específicos, para objetivos específicos (cf. SCRIBNER e COLE, 1981) [...] O fenômeno do letramento, então, extrapola o mundo da escrita tal qual ele é concebido pelas instituições que se encarregam de introduzir formalmente os sujeitos no mundo da escrita. (KLEIM AN, 1995, p. 15-20).

D essa forma, não parece difícil concluir que a melhoria da qualidade do trabalho pedagógico com Arte na educação infantil e nas séries iniciais do ensino fundamental passa necessariamente por uma compreensão do letramento como prática complexa sociocultural, historicamente constituída, seja dos professores que atuam nesses níveis da escolarização, seja dos propositores e formuladores das matrizes curriculares dos cursos (in)formativos dos profissionais da educação. 0 entendimento da importância do desenvolvimento omnilateral (em todas as direções) do ser humano implica (re)conhecer as múltiplas dimensões do saber-fazer pedagógico e a especificidade heurística das diferentes áreas do conhecimento - sem prejuízo do diálogo entre elas ou da interdisciplinaridade.

$\mathrm{N}$ ão é tarefa deste artigo discutir exaustivamente o documento da C omissão de Educação e Cultura da C âmara dos D eputados - mencioná-lo aqui serve de alerta para as investidas 'na calada da noite' de um tipo deliberadamente 'míope' de conceptualização da atividade educacional que se encontra, indisfarçada e cinicamente, a serviço do fetichismo mercantilista transnacional:

A maioria dos países faz uma importante distinção entre a formação e a necessidade permanente de atualização - que são responsabilidades individuais do professor - e a capacitação que é oferecida pelas escolas ou sistema de ensino. Em nenhum caso a 
capacitação é vista como substituto da formação inicial básica. A capacitação de professores existe em todos os países, tendo mais ênfase em países como os Estados U nidos do que na Europa. N os países de cultura alemã, a iniciação profissional do professor é fortemente supervisionada. $\mathrm{Na}$ maioria dos países, a capacitação é concentrada em um a dois dias por ano - raramente mais de 20 horas por ano - e tipicamente se concentra em: disseminar informações sobre novos programas; apresentar conceitos, instrumentos ou inovações metodológicas associadas a esses programas. (BRASIL, 2003, p. 145).

Em momento algum se procurou defender aqui uma substituição da (in)formação acadêmico-institucional dos profissionais da educação por programas pontuais de 'capacitação' de professores com duração de 20 horas por ano. 0 que se fez, ao longo do texto, foi apontar o modelo prático-reflexivo de (in)formação docente como uma via alternativa útil para a 'correção' emergencial de algumas distorções curriculares constatadas em programas preparatórios do professor da educação infantil e das séries iniciais do ensino fundamental, particularmente no que se refere ao ensino de Arte.

Pensamos que, paralelamente à tradicional ênfase no saber, as universidades e agências (in)formadoras do(a) professor(a) devem cuidar também para que 0 saber-fazer (a prática pedagógica com Arte) e 0 ser (0 exercício cidadão pela profissão docente) recebam igual atenção dos propositores e formuladores de suas matrizes curriculares.

É preciso, no entanto, reconhecer que o documento da Câmara dos D eputados possui aspectos positivos, como o fato de socializar os atuais saberes constituídos pela vertente cognitivista das abordagens ao letramento. M as 0 modo como as conquistas dessa escola da Psicologia são ali apresentadas - como se fossem a 'última palavra' nos estudos sobre os processos de aquicição da lectoescrita - diminui o merecido valor do trabalho realizado pelo G T Alfabetização Infantil: os novos caminhos.

$\mathrm{N}$ ão existem verdades absolutas, tampouco um único e 'correto' ponto de vista a respeito das complexas questões que se relacionam com o letramento. $A$ perspectiva da Ciência Cognitiva para abordar a lecto-escrita - advogada eloqüentemente pela C omissão de Educação e Cultura da Câmara - é apenas um 
lugar epistemológico no vasto continente do conhecimento acadêmico de análise da apropriação da cultura letrada, uma perspectiva a mais entre outras - todas ocupadas em compreender e explicar os fenômenos da natureza humana em suas múltiplas dimensões - biológica, social, histórica, cultural, psicológica etc.

A denúncia da existência de uma 'febre' de programas de (in)formação em serviço promovidos pelas Secretarias de Educação dos Estados e Municípios, trazida a público pelo documento, é todavia pertinente. $\mathrm{N}$ ão se pode acreditar que esses programas possam, por si mesmos, solucionar definitivamente a problemática relativa aos processos (in)formativos dos profissionais da educação no país. Sua eficácia só se daria paralelamente a todo um conjunto organizado de ações tendo em vista a melhoria da qualidade da educação brasileira [como a Reforma Universitária, o Sistema N acional de Avaliação da Educação Superior (SINAES), o aperfeiçoamento democrático da administração escolar, a remuneração digna dos trabalhadores da educação, a melhoria das condições físicas e materiais para o desenvolvimento do trabal ho docente etc].

Outro ponto positivo do relatório final do GT Alfabetização Infantil da Comissão de Educação e Cultura da Câmara dos Deputados é o fato de problematizar as concepções educacionais subjacentes ao texto dos Parâmetros Curriculares Nacionais (PCN s). M as a crítica aos PCN s constitui um patético 'lamento', em razão de a escola da Psicologia conhecida como Ciência Cognitiva não ter sido ali suficientemente enfatizada.

As profundas contradições epistemológicas presentes na fundamentação teórica dos textos que se prestam a justificar e expor, nos PCN s, as propostas disciplinares de diferentes áreas do conhecimento e a orientação 'de cima para bai xo', que caracterizou o processo de sua elaboração e implantação no país, não são suficientemente exploradas pelo documento da Câmara dos Deputados, tampouco o descompasso entre a dimensão discursiva dos PCN s e a ausência de macropolíticas educacionais voltadas para a melhoria da escolarização nacional, como constatou o professor Fábio do N ascimento Fonsêca (2001, p. 29), da U niversidade Federal da Paraíba (U FPB):

Ao se afirmarem, reiteradamente, como um instrumento para a obtenção da qualidade da educação, os PCN s parecem supor que a simples existência de uma proposta curricular seja condição suficiente para 
resolver a problemática que afeta a educação brasileira, desconsiderando os determinantes estruturais que respondem pelo fracasso da escola pública eque envolvem questões que vão da desvalorização do magistério à falta de condições materiais e de infra-estrutura para a realização da tarefa pedagógica do ensino e da aprendizagem.

\section{Considerações finais}

A complexidade pedagógica da proposta metodológica triangular para 0 ensino de Arte (fazer-apreciar-contextualizar) solicita uma sólida fundamentação teórico-prática dos princípios educacionais das diferentes linguagens artísticas por parte do professor da educação infantil e das séries iniciais do ensino fundamental (BARBOSA, 1996). M as a implementação do modelo triangular para o trabalho pedagógico com as artes na escolarização, por exemplo, requer sobretudo no que diz respeito ao eixo apreciação - o desenvolvimento de toda uma rede de apoio às manifestações artísticas e de incentivo à produção cultural nacional (DESGRANGES, 2003).

Como possibilitar às crianças de um vilarejo no interior da Bahia a apreciação da grandiosidade cênica de um musical infantil como A Bela ea Fera? Como permitir que as crianças dos grandes centros urbanos desfrutem a beleza de um autêntico Bumba-M eu-Boi maranhense? 0 uso do vídeo, da TV e do cinema seria a solução? N ão é verdade que a espetacularidade do Bumba-M euBoi ou o impacto cênico do musical infantil, se filmados, já não mais seriam linguagem teatral? A relação presencial que se estabelece entre atuantes e observadores nos eventos espetaculares é insubstituível e constitui a especificidade da linguagem cênica.

$N$ ão é possível, no âmbito de um pequeno artigo, dar conta de 'cobrir' toda a complexidade e os múltiplos aspectos que assume o trabalho pedagógico com as Artes nos níveis iniciais da escolarização. $M$ as acreditamos ter fornecido ao leitor al gum alimento para a discussão dos atuais desafios postos aos processos de (in)formação docente sobre o ensino de Arte. Procuramos aqui - ainda que de modo breve - situar o leitor na perspectiva contemporânea dos processos (in)formativos do profissional da educação no país, fornecendo-lhe um ponto de 
KEY WORDS: Art teaching. Arteducation. Child education. Reflective practitioner paradigm. Teaching programs. vista que - temos certeza - é compartilhado por alguns educadores comprometidos em discutir e pensar as questões relativas à qualificação dos trabalhadores da educação infantil e das séries iniciais do ensino fundamental, equacionando-as. Demonstramos também algumas possibilidades da (in)formação continuada e em serviço de professores, ancorada no paradigma prático-reflexivo de Schön para o trabalho pedagógico com Arte. Q uestionamos ainda o caráter excludente da concepção mecanicista do letramento (alfabetização), que caracteriza a vertente cognitivista na abordagem do processo de apropriação da cultura letrada.

Evidentemente, não se pode perder de vista o entendimento de que "a escola é sempre construção dos sujeitos sociais, que se apropriam de determinado modo da escola e das determinações sociais e estatais a partir das suas histórias particulares, e de suas experiências" (SAWAYA, 2002, p. 205). Então, não sejamos ingênuos: a melhoria da qualidade da educação nacional requer vontade coletiva e compromisso das agências e instituições (in)formadoras com o traçado de um novo perfil profissional dos trabalhadores da escolarização. M as daí a cruzarmos os braços e esperarmos a coisa ser resolvida por meio das macropolíticas educacionais é, no nosso entendimento, ausência de responsabilidade cidadã "quem sabe faz a hora" já disse uma vez o poeta Vandré.

Hoje, estamos convencidos de que as micropolíticas afirmativas e de resistência cotidianas, no dia-a-dia da prática docente - em sala de aula e fora dela - é que fundamental mente (re)dimensionam o poder revolucionário da educação.

\section{Challenges Of THE TEACHING (IN)FORMATION: THE PEDAGOGICAL WORK WITH ARTS IN THE 'SCHOOLARIZATION'}

ABSTRACT: The article discusses the room of art teaching in Brazilian teaching programs and signs Schön's reflective practitioner model as an alternative way to correct some distorted features of these programs. Some results from participant observations developed by the author are depicted in help of his theoric arguments. It also considers diferent approaches to literacy by macro and micro educational policies in Brazilian schooling. 


\section{REFERÊNCIAS}

Azen ha, M aria da Graça. Imagens e letras. São Paulo: Ática, 1995.

Barbo SA, Ana M ae. A imagem no ensino de arte. São Paulo: Perspectiva, 1996.

BRASIL. Comi ssão de educação e cultura: grupo de trabalho alfabetização infantil - relatório final apresentado no seminário ' 0 poder legisativo e a alfabetização infantil: os novos caminhos' (D ocumento não publicado). Braślia, D F: Câmara dos D eputados, 2003.

Brasil. Ministério da Educação e Cultura (MEC). Secretaria de Educação Fundamental. Referencial curricular nacional de educação infantil, v. 1-3. Braślia, DF: MEC-SEF, 1998.

BRASIL. Ministério da Educação (MEC). Secretaria de Educação Fundamental. Parâmetros Curriculares Nacionais, v. 1-10. Brasília, D F: M EC -SEF, 1997.

CAM ILLIS, Lourdes Stamato de. Criação e docência em arte. Araraquara: JM Editora, 2002.

Deheizelin, M onique. Por um triz: arte e cultura - atividades e projetos educativos. São Paulo: Paz e Terra, 1998.

Desgranges, Flávio. Pedagogia do espectador. São Paulo: Hucitec, 2003.

Ferraz, M aria H eloísa C. de T.; Resende e Fusari, M aria F de. M etodologia do ensino de arte. São Paulo: Cortez, 1993a.

. Arte na educação escolar. São Paulo: Cortez, 1993b.

FerReIRA, Suely. Imaginação e linguagem no desenho da criança. Campinas: Papirus, 1998.

Fo N SÊCA, Fábio do $N$ ascimento. Parâmetros Curriculares $N$ acionais: possibilidades, limites e implicações. In: PENNA, M aura (org.). É ete o ensino de arte que queremos? U ma análise das propostas dos Parâmetros Curriculares N acionais. João Pessoa: Universitária U FPB, 2001. JaPIASSU, Ricardo Ottoni Vaz. M etodologia do ensino de teatro. Campinas: Papirus, 2003a.

- Jogos teatrais na préescola: 0 desenvolvimento da capacidade estética na educação infantil (Tese de doutorado não publicada). São Paulo: Faculdade de Educação da Universidade de São Paulo (USP), 2003b. 
- Criatividade, criação e apreciação artísticas: a atividade criadora segundo Vygotsky. In: VASCONCELOS, Mário S. (org.). Criatividade: psicologia, educação e conhecimento do novo, p. 43-58. São Paulo: M oderna, 2001.

KLEIM AN, Ângela B. (org.). Os significados do letramento: uma nova perspectiva sobre aprática social da escrita. Campinas: M ercado das Letras, 1995.

Levin, Esteban. A garatuja como vestígio das letras. Estilos da clínica: revista sobre a infância com problemas, n. 4.1, p. 120-123. São Paulo: Instituto de Psicologia da Universidade de São Paulo (USP), 1998.

LURIA, A. N. 0 desenvolvimento da escrita na criança. In: Leontiev, A. N .; LURIA A. R.; VYG OTSKY, L. S. Linguagem, desenvolvimento e aprendizagem, p. 143-189. São Paulo: Edusp/Ícone, 1994.

M ARín, Rolando Valdés. El desarrollo psicográfico del niño. H avana: Científico-T écnica, 1985.

M oreira, Ana Angélica A. 0 espaço do desenho: a educação do educador. São Paulo: Loyola, 1984.

Newman, Fred; Holzaman, Lois. Lev Vygotsky: cientista revolucionário. São Paulo: Loyola, 2002.

O LIVEIRA, M arta Kohl de. et al. Psicologia, educação e as temáticas da vida cotidiana. São Paulo: M oderna, 2002.

Penn A, M aura (org.). É este o ensino de arte que queremos? U ma análise das propostas dos Parâmetros Curriculares N acionais. João Pessoa: Universitária U FPB, 2001.

PILLAR, Analice D utra. D esenho e construção de conhecimento na criança. Porto Alegre: Artes M édicas, 1996a. $1996 \bar{b}$

. D esenho \& Escrita como sistemas de representação. Porto Alegre: Artes M édicas,

Fazendo artes na alfabetização: artes plásticas e alfabetização. Porto Alegre: GEEPA/Kuarup, 1993.

Rocco, M aria Tereza F. Acesso ao mundo da escrita: os caminhos paralelos de Luria e Ferreiro. Cadernos de Pesquisa, n. 75, p 25-33. Campinas: Autores Associados, nov. 1990. 
SAntana, Arão P. de. Teatro e formação de professores. São Luiz: Edufm A, 2000.

SawAYA, Sandra M aria. N ovas perspectivas sobre 0 sucesso e 0 fracasso escolar. In: Psicologia, educação e as temáticas da vida cotidiana, p. 197-213. São Paulo: M oderna, 2000.

ScHöN, D onald. Educating the reflective practitioner. São Francisco: Jossey-bass Publishers, 1987.

VYGOTSKY, L. S. Psicologia pedagógica. São Paulo: M artins Fontes, 2001. . Psicologia da arte. São Paulo: M artins Fontes, 1998. . A formação social da mente. São Paulo: M artins Fontes, 1996. . La imaginación y el arte en la infancia (ensayo psicológico). M adri: Akal, 1982. 
E

84 